\title{
Structural Characteristics and Sulfur Isotope Compositions of Laboratory Sulfurized Carbohydrates and DOM
}

Josef P. Werne ${ }^{1}$, MOLly D. O’BeIRnE ${ }^{1,2}$, MORGAN R. RAVEN $^{2}$, BART. E. VAN DONGEN ${ }^{3}$, AliCE BOSCOSANTOS ${ }^{4}$, WiLliAM P. GILHOOLY III ${ }^{4}$

${ }^{1}$ Dept of Geology and Environmental Science, Univ Pittsburgh, PA, USA, jwerne@pitt.edu

${ }^{2}$ Dept of Earth Science, Univ California, Santa Barbara, CA, USA,mdobeirne@pitt.edu

${ }^{3}$ School of Earth and Environmental Sciences, Univ Manchester, Manchester, UK

${ }^{4}$ Dept of Earth Sciences, Indiana Univ-Purdue Univ Indianapolis, Indiana, USA

Organic sulfur is the second largest pool of reduced sulfur after pyrite and has long been a topic of interest due to connections to the global biogeochemical cycles of sulfur, carbon, oxygen, and iron, microbial activity, and organic matter $(\mathrm{OM})$ preservation. The identification of organic sulfur compounds (OSC) on Mars suggests that sulfurization may be a pathway of $\mathrm{OM}$ preservation on other planets as well. Carbohydrates are generally thought to be preferentially degraded during early diagenesis and as such, are not extensively preserved in the sedimentary record; however, preservation of carbohydrates over geologic timescales has been linked to sulfur incorporation during early diagenesis, producing a sulfur-rich high-molecular weight (HMW) organic matrix resistant to remineralization. HMW OSC comprise a significant proportion of kerogen - the largest pool of OM on Earth, and also the least well understood in terms of formation mechanisms and structural components. Here, we sulfurized glucose and humic acid under environmentally relevant conditions (aqueous mixtures of (poly)sulfides, inert atmosphere, $24^{\circ} \mathrm{C}$ ). Our focus is on understanding the sulfur isotopic fractionation associated with sulfur incorporation into carbohydrates and dissolved organic matter (DOM) and the resulting structures of OSC derived from this process. Structural analysis indicates that hydroxyl groups have a role in the formation of (poly)sulfide crosslinked carbohydrates and sulfur-rich macromolecular OM in the environment. Varying sulfur isotopic fractionation between reduced sulfur species and organic substrates under different sulfurization reaction conditions may be related to the relative proportion of $\mathrm{C}-\mathrm{S}$ to $\mathrm{S}-\mathrm{O}$ bonds within a macromolecular matrix. Similarities among laboratory sulfurized glucose and DOM show that similar reaction mechanisms occur during natural sulfurization processes. 